\title{
Extracellular overexpression of recombinant Thermobifida fusca cutinase by alpha-hemolysin secretion system in E. coli BL21(DE3)
}

Lingqia Su ${ }^{1,2}$, Sheng Chen ${ }^{1,2}, \mathrm{Li} \mathrm{Yi}^{3}$, Ronald W Woodard ${ }^{3}$, Jian Chen ${ }^{1,2}$ and Jing $\mathrm{Wu}^{1,2^{*}}$

\begin{abstract}
Background: Extracellular expression of proteins has an absolute advantage in a large-scale industrial production. In our previous study, Thermobifida fusca cutinase, an enzyme mainly utilized in textile industry, was expressed via type II secretory system in Escherichia coli BL21(DE3), and it was found that parts of the expressed protein was accumulated in the periplasmic space. Due to the fact that alpha-hemolysin secretion system can export target proteins directly from cytoplasm across both cell membrane of $E$. coli to the culture medium, thus in the present study we investigated the expression of cutinase using this alpha-hemolysin secretion system.

Results: T. fusca cutinase was fused with the specific signal peptide of alpha-hemolysin scretion system and expressed in E. coli BL21(DE3). In addition, HlyB and HlyD, strain-specific translocation components of alphahemolysin secretion system, were coexpressed to facilitate the enzyme expression. The cultivation of this engineered cell showed that cutinase activity in the culture medium reached $334 \mathrm{U} / \mathrm{ml}$, which is 2.5 times that from type II secretion pathway under the same culture condition. The recombinant cutinase was further purified. Biochemical characterization of purified enzyme, which had an $\alpha$-hemolysin secretion pathway signal peptide attached, had substrate specificity, pH and temperature profile, as well as application capability in bioscouring similar to that of wild-type cutinase.

Conclusions: In the present study, T. fusca cutinase was successfully secreted to the culture media by $\alpha$-hemolysin secretion system. This is the first report of cutinase being efficiently secreted by this pathway. Due to the limited cases of successful expression of industrial enzyme by $E$. coli $\alpha$-hemolysin secretion system, our study further explored the utilization of this pathway in industrial enzymes.
\end{abstract}

Keywords: alpha-hemolysin secretion pathway, cutinase, protein secretion, extracellular production

\section{Background}

Generally, extracellular expression of proteins has an absolute advantage in a large-scale industrial production. Escherichia coli, the most widely used host, has five protein secretion pathways, in which, the vast majority of recombinant proteins are secreted using the SecBdependent type II pathway. In this process, the pre-protein is first transferred across the inner membrane, folded in the periplasm, and then secreted into the culture medium, usually by nonspecific periplasmic leakage

\footnotetext{
* Correspondence: jingwu@jiangnan.edu.cn

'State Key Laboratory of Food Science and Technology, Jiangnan University, 1800 Lihu Ave, Wuxi, Jiangsu 214122, China

Full list of author information is available at the end of the article
}

[1]. Due to this two-step process, the recombinant protein is sometimes partially located in the extracellular medium and partially in the periplasm, affecting the total extracellular yields $[2,3]$.

By contrast, type I secretion systems (TISS) export their native passenger proteins or recombinant proteins/ peptides such as repeats-in-toxin (RTX) proteins, proteases and lipases directly into the culture medium without accumulation in the periplasmic space [4-9]. The best-characterized and most widely used TISS is the $\alpha$ hemolysin (HlyA) secretion pathway from uropathogenic E. coli [10]. The secretory machinery of this pathway consists of three components: HlyB, an ATP-binding cassette ( $\mathrm{ABC}$ transporter); HlyD, a membrane fusion

\section{Biomed Central}

(C) 2012 Su et al; licensee BioMed Central Ltd. This is an Open Access article distributed under the terms of the Creative Commons Attribution License (http://creativecommons.org/licenses/by/2.0), which permits unrestricted use, distribution, and reproduction in any medium, provided the original work is properly cited. 
protein; and TolC, an outer membrane protein. The three components can form a trans-membrane channel connecting both inner and outer membranes of cell, through which HlyA can be transferred directly to the extracellular medium. In this pathway, the signal peptide, which is located in the C-terminus of HlyA, is not cleaved after translocation and remains in the target protein as the final product [11].

In addition to HlyA, proteins ranging in size from 50 to over 4000 amino acids, with C-terminally fused HlyA signal sequence (HlyAs), can also be recognized and secreted via the HlyB-HlyD-TolC translocator $[1,11]$. The $\alpha$-hemolysin secretion pathway has mainly been reported in uropathogenic E. coli. HlyB and HlyD have been generally considered strain specific proteins, TolC, in contrast, is a component of multiple trans-membrane systems in many microorganisms. Thus, co-expression of $\mathrm{HlyB} / \mathrm{D}$ is often performed to facilitate the extracellular translocation of proteins utilizing the $\alpha$-hemolysin secretion pathway during expression in host strains other than uropathogenic E. coli [12]. So far, this approach has most often been applied to the expression of proteins involved in immunological and vaccine research, especially in the recombinant antigen presentation through live-attenuated bacterial vaccine strains [11,13-15], there were only several cases of successful extracellular expression of industrial enzymes, such as lipase [16], protease [15], cyclodextrin glucanotransferase [17], alkaline phosphatase [18]. Recent reports about $\alpha$-hemolysin secretion pathway have focused on the effects of translated protein folding rate and mutagenesis of HlyAs, HlyB or HlyD on the efficiency of translocation $[15,17,19]$.

Cutinase is a multi-functional esterase, which shows hydrolytic activity (cutin and a variety of soluble synthetic esters, insoluble triglycerides and polyesters), synthetic activity and transester activity [20-28]. Therefore, it is an important industrial enzyme. Especially, due to the capacity of hydrolyzing the cutin structure in the cuticle of cotton fiber, it has potential application in environmentally friendly bioscouring [29]. Previously, cutinase from Thermobifida fusca was cloned and extracellularly expressed in E. coli BL21(DE3) through type II secretory system in our laboratory [30]. Large amounts of cutinase were found in the periplasmic space [22]. In the present study, we showed that the T. fusca cutinase could be efficiently secreted to the external medium through $\alpha$-hemolysin secretion pathway without a periplasmic intermediate. In addition, detailed characterization showed that the recombinant enzyme, even with cterminal signal peptide attached, has similar properties to that of wild-type cutinase.

\section{Results and discussion}

\section{Construction of recombinant plasmids}

In order to use E. coli BL21(DE3) to express recombinant protein into the growth medium through the $\alpha$ hemolysin secretion pathway, the $\alpha$-hemolysin specific signal peptide HlyAs, which corresponds to residues 965-1024 of $\alpha$-hemolysin, was fused to the C-terminus of $T$. fusca cutinase by overlapping PCR. The PCR products were cloned into the T7-driven expression vector pET-20b(+), resulting in the recombinant plasmids cutinase-HlyAs/pET-20b(+). In addition, the genes encoding the components of translocator, HlyB and HlyD, were amplified together by PCR using E. coli CFT073 genomic DNA as template, and cloned into the expression vector pSTV28, resulting in HlyBD/pSTV28.

\section{Extracellular secretion of recombinant cutinase-HlyAs}

To create an extracellular expression system for cutinase via the $\alpha$-hemolysin secretion pathway, the E. coli BL21 (DE3) strain was co-transformed with two plasmids: cutinase-HlyAs/pET-20b(+) and HlyBD/pSTV28. Since the two plasmids contain different replication origins, they have capability of co-existing in one bacterial cell. When subsequently grown in TB medium, the cutinase activity in the culture medium reached $334 \mathrm{U} / \mathrm{ml}$ at 48 $\mathrm{h}$ (Figure 1B), which is 2.5 fold to that of the culture by a recombinant strain constructed previously in which cutinase was secreted through $E$. coli secB-dependent type II pathway [30]. The protein concentration of expressed enzyme was $1.5 \mathrm{mg} / \mathrm{mL}$, which represents the highest yield of cutinase ever reported in the culture medium $[2,31,32]$. No significant difference in cell growth was observed between these two engineered strains (Figure 1A).

\section{Purification of cutinase-HlyAs}

In $\alpha$-hemolysin secretion pathway, the signal peptide (HlyAs) will not be cleaved after translocation [12] and remained in the final protein product, which is cutinaseHlyAs in our case. Cutinase-HlyAs was purified from culture supernatant by ammonium sulfate precipitation and anion exchange (DEAE-Sepharose, monoQ) chromatography. The purification process is summarized in Table 1 . The purified cutinase-HlyAs was determined to be homogeneous by SDS-PAGE (Figure 2) and exhibited a specific activity of $446.2 \mathrm{U} / \mathrm{mg}$ using the substrate pNPB, which is similar to that of cutinase activity [30].

\section{Temperature Optimum and Thermostability of Cutinase- HlyAs}

Recombinant cutinase-HlyAs exhibited optimal activity at $70^{\circ} \mathrm{C}$, and the enzyme activity decreased sharply from 
(A)

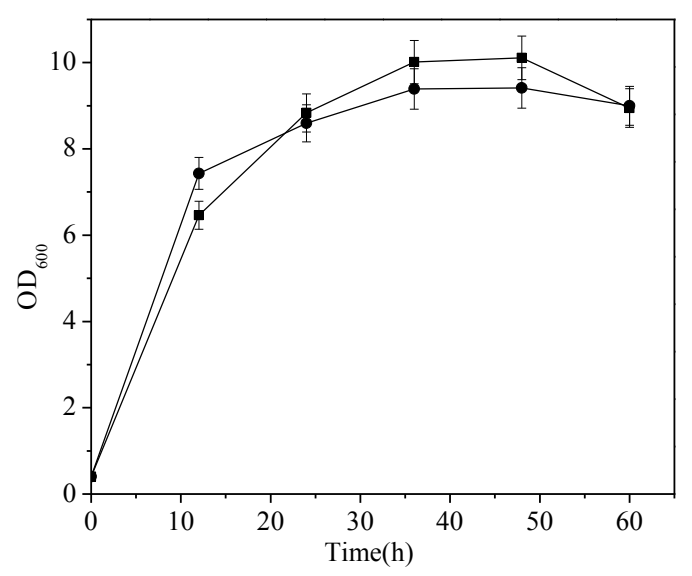

(B)

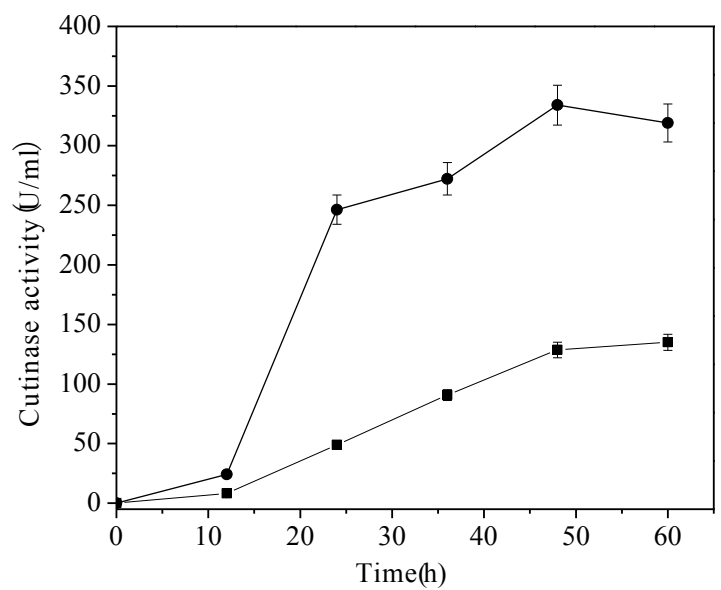

Figure 1 Cell growth(A) and the production of recombinant cutinase(B). (•) type I secretion pathway; (-) type I| secretion pathway. The error bars show the standard deviations from three measurements.

70 to $80^{\circ} \mathrm{C}$, while cutinase displayed its highest enzyme activity at $60^{\circ} \mathrm{C}$ (Figure 3a).

The thermostability of cutinase-HlyAs was determined at $50^{\circ} \mathrm{C}$. Interestingly, cutinase-HlyAs exhibited greater thermostability than cutinase, with $70 \%$ residual activity after incubation for $80 \mathrm{~h}$, while the cutinase showed only $50 \%$ residual activity under the same conditions (Figure 3b). The phenomena of this improved thermostability were also found in some other kinds of chimeric proteins [33,34]. Although the mechanism for this improvement is not clear, it may related to protein structure as well as its folding. Further studies are needed to explore this issue.

\section{pH Optimum and Stability of Cutinase-HlyAs}

Cutinase-HlyAs exhibited optimal activity at $\mathrm{pH}$ 8.0, which is similar to the behavior of cutinase (Figure 4a), although the shapes of their $\mathrm{pH}$-rate curves are somewhat different. Cutinase-HlyAs activity is more sensitive to $\mathrm{pH}$, especially in the alkaline range. A pH-stability investigation was performed from $\mathrm{pH} 4$ to $\mathrm{pH} 11$ (Figure $4 \mathrm{~b}$ ). Cutinase-HlyAs retained more than $90 \%$ of its maximal activity after incubation at $37^{\circ} \mathrm{C}$ for $24 \mathrm{~h}$ in the $\mathrm{pH}$ range 4-11, which is superior to that of cutinase.

\section{Cutin Hydrolyzing Activity of Cutinase-HlyAs}

In addition to its ability to hydrolyze a short-chain ester (pNPB), cutinase can also catalyze the cleavage of the polyester bonds of cutin, which is composed mainly of C16 and C18 fatty acids. To determine the catalytic efficiency of cutinase-HlyAs toward cutin, both cutinase and cutinase-HlyAs were subject to assay using cutin as substrate. As shown in Table 2 the proportion of C16 and C18 family fatty acid monomers released after enzymatic reaction were $72.13 \%$ for cutinase-HlyAs and $71.84 \%$ for cutinase. The hydroxy fatty acids, which are the characteristic cutin components, were $1.95 \%$ for cutinase-HlyAs and $1.80 \%$ for cutinase. These results confirmed that cutinase-HlyAs can hydrolyze cutin as efficiently as cutinase.

\section{Catalytic Activity of Cutinase-HlyAs toward Cotton fiber/ Wettability of Cotton Fabric}

Cutinase can improve the wettability of cotton fiber by hydrolyzing the cutin of its waxy cuticle layer, a process referred to as bioscouring. The ability of any particular cutinase preparation to increase wettability is assessed by determining its effect on the wetting time of cotton. To assess the efficacy of cutinase-HlyAs, cotton fiber

Table 1 Summary of the purification of cutinase-HlyAs

\begin{tabular}{|c|c|c|c|c|c|}
\hline Purification step & $\begin{array}{c}\text { Total protein } \\
\text { (mg) }\end{array}$ & $\begin{array}{c}\text { Total activity } \\
\text { (U) }\end{array}$ & $\begin{array}{c}\text { Specific activity } \\
(\mathrm{U} / \mathrm{mg})\end{array}$ & $\begin{array}{c}\text { Yield } \\
(\%)\end{array}$ & $\begin{array}{l}\text { Purification } \\
\text { (fold) }\end{array}$ \\
\hline Crude extract & 584.9 & 128497.5 & 219.7 & 100 & 1 \\
\hline Ammonium sulfate fraction & 481.7 & 113334.8 & 235.3 & 88.2 & 1.1 \\
\hline DEAE Sepharose purification & 129.9 & 51369.9 & 395.5 & 40.0 & 1.8 \\
\hline MonoQ purification & 68.8 & 30681.8 & 446.2 & 23.9 & 2.0 \\
\hline
\end{tabular}




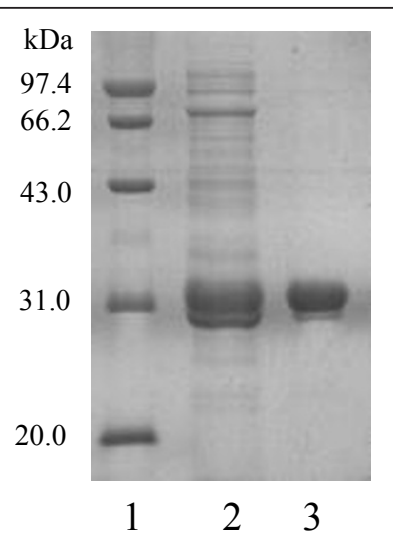

Figure 2 SDS-PAGE analysis of the purification of cutinaseHlyAs in E. coli. Lane 1, molecular mass standard protein; Lane 2, supernatant of cutinase-HlyAs; and Lane 3, purified cutinase-HlyAs.

samples were incubated with either cutinase or cutinaseHlyAs. The wetting times were $15 \mathrm{~s}$ for cutinase and $15.8 \mathrm{~s}$ for cutinase-HlyAs, while inactivated enzymes showed no effect on the wettability of cotton fabric. HlyAs didn't affect the application of recombinant cutinase in bioscouring.

\section{Conclusions}

In the present study, with concomitant co-expression of $\mathrm{HlyB} / \mathrm{D}$, we explored the extracellular expression of $T$. fusca cutinase via $\alpha$-hemolysin secretion pathway in $E$. coli BL21(DE3). As the expression experiment in the culture media showed, a $334 \mathrm{U} / \mathrm{mL}$ of cutinase activity $(1.5 \mathrm{mg} / \mathrm{mL}$ target proteins) was achieved. In addition, the recombinant protein was purified and the detailed characterization of purified enzyme showed that the recombinant cutinase, even though with c-terminal signal peptide attached, had substrate specificity, $\mathrm{pH}$ and temperature profile, as well as application capability in bioscouring similar to that of wild-type cutinase. This is the first report of recombinant $T$. fusca cutinase being efficiently secreted by the $\alpha$-hemolysin secretion system. Due to the limited cases of successful expression of industrial enzyme by $E$. coli $\alpha$-hemolysin secretion system, our study further explored the utilization of this pathway in industrial enzymes.

\section{Methods}

\section{Bacterial Strains, Vectors and Materials}

The plasmid cutinase/pET-20b(+), for expressing cutinase through E. coli SecB-dependent type II pathway using pelB as signal peptide, was constructed previously [30]. E. coli CFT073(ATCC 700928) were purchased from ATCC. E. coli JM109 was used as the host for plasmid construction. E. coli BL21(DE3) was used as expression host. The T. fusca strain was laboratory stock [30]. TOPO TA cloning kit was obtained from Invitrogen. The pMD18-T simple vector and the plasmid pSTV28 were obtained from TakaRa (Dalian, China). The pET-20b(+) vector from Novagen was utilized as expression vector.

\section{Plasmid Construction}

All the primers for gene cloning and plasmid construction are shown in Table 3. The gene encoding cutinase (Tfu_0883, GenBank: YP_288944) lacking its stop codon and $\mathrm{N}$-terminal signal peptide was amplified using plasmid cutinase/pET-20b(+) as template. The gene encoding $\alpha$-hemolysin specific signal peptide HlyAs

\section{(A)}

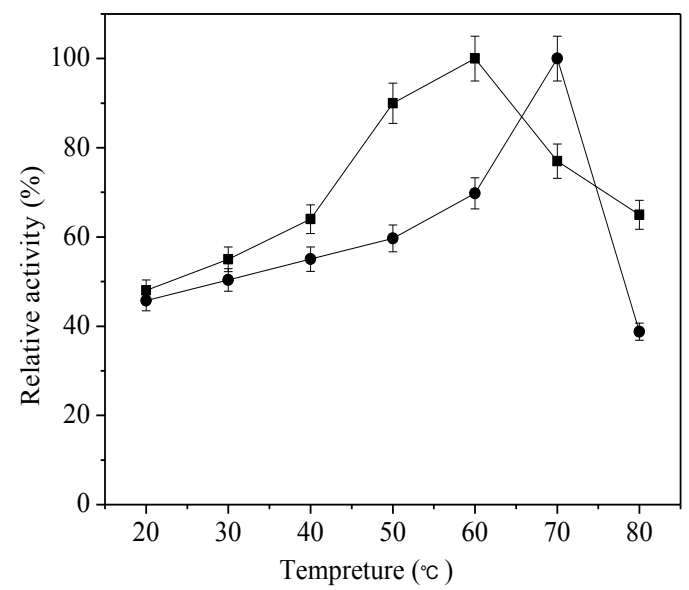

(B)

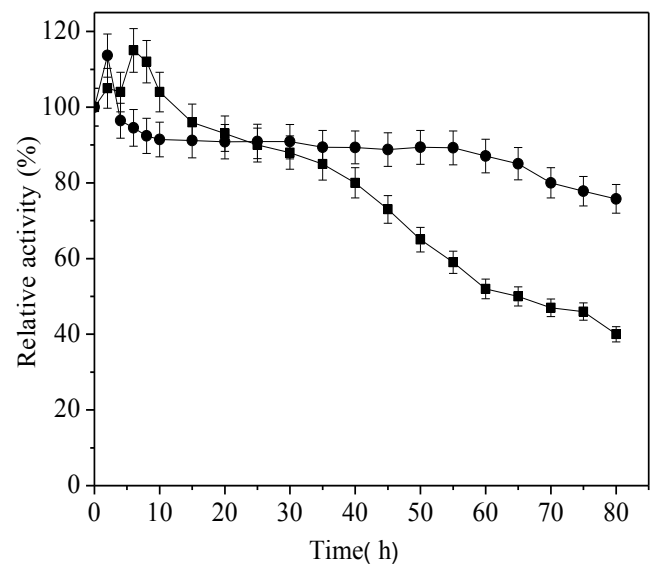

Figure 3 Effects of temperature on activity and stability of cutinase-HlyAs and cutinase. (A) Temperature optimum determined in Tris-HCl buffer (pH 8.0); (B) Thermostability of the enzymes in Tris- $\mathrm{HCl}\left(\mathrm{pH} \mathrm{8.0)}\right.$ at $50^{\circ} \mathrm{C}$. $\bullet$, cutinase; $\bullet$, cutinase-HlyAs. The error bars show the standard deviations from three measurements. 
(A)

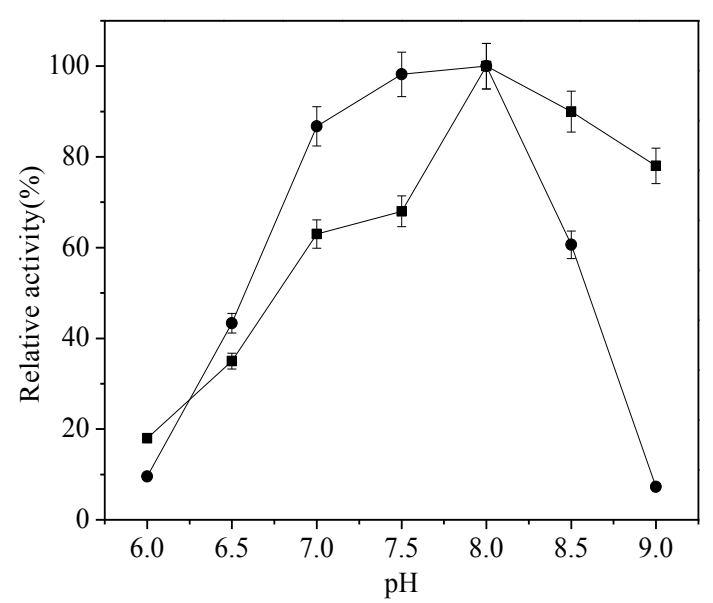

(B)

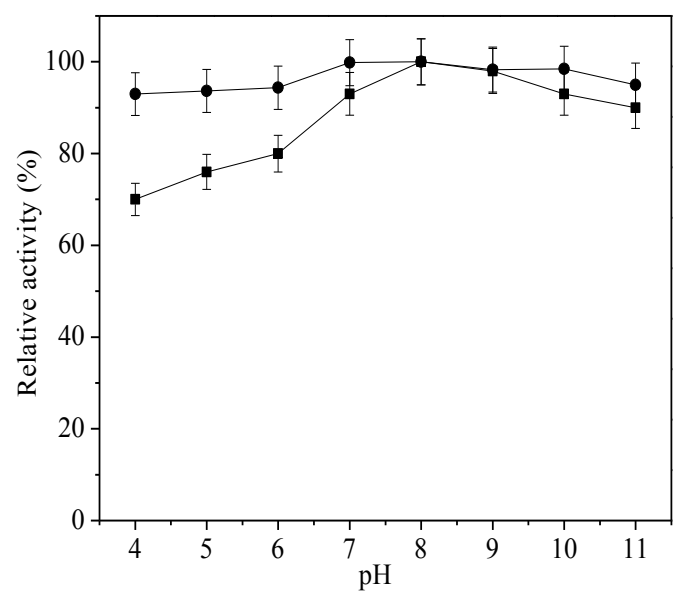

Figure 4 Effects of $\mathrm{pH}$ on activity and stability of cutinase-HlyAs and cutinase. (A) pH optimum. The samples were determined in the following buffer-potassium phosphate ( $\mathrm{pH}$ 6.0-7.0) and Tris- $\mathrm{HCl}$ ( $\mathrm{pH}$ 7.0-9.0). (B) $\mathrm{pH}$ stability. The samples were assayed after incubation $24 \mathrm{~h}$ at $37^{\circ} \mathrm{C}$ in various buffers-sodium acetate buffer( $\mathrm{pH}$ 4.0-6.0), potassium phosphate buffer ( $\mathrm{pH}$ 6.0-7.0), Tris- $\mathrm{HCl}$ buffer ( $\mathrm{pH}$ 7.0-9.0), and glycine- $\mathrm{NaOH}$ buffer (pH 9.0-11.0). - , cutinase; $\bullet$ cutinase-HlyAs. The error bars show the standard deviations from three measurements.

(GenBank: NP_755445.1, 965-1024 amino acid residue of HlyA) was amplified using E. coli CFT073 genomic DNA as template. Overlapping PCR was utilized to fuse HlyAs to the C-terminal of cutinase using primers cutinase-F, cutinase-HlyAs-F, cutinase-HlyAs-R and HlyAs$\mathrm{R}$, where underlined bases represented NdeI and XhoI restriction sites, respectively. The amplification product was gel-purified, ligated into the vector pMD18T-simple to form plasmid cutinase-HlyAs/pMD18-T simple. To eliminate the internal NdeI site in HlyAs, site-directed mutagenesis was performed using plasmid cutinaseHlyAs/pMD18-T simple as template, HlyAs-MF and HlyAs-MR as primers, in which the lower-case letters indicate the position of silent mutations. The plasmid with the correctly mutated sequences, which was confirmed by DNA sequencing, was digested with $\mathrm{NdeI}$ and XhoI. The target fragment was then ligated into the similarly restricted expression vector pET-20b(+), resulting in the recombinant plasmid cutinase-HlyAs/pET-
$20 \mathrm{~b}(+)$, in which the intrinsic pelB signal peptide in pET-20b(+) vector was eliminated.

The genes encoding HlyB (GenBank: NP_755448) and HlyD (GenBank: NP_755449) were cloned from E. coli CFT073 genomic DNA using primers HlyBD-F and HlyBD-R, where the underlined bases represented SacI and $\mathrm{BamHI}$ restriction sites. The amplification product was gelpurified, and ligated into $\mathrm{PCR}^{\mathbb{R}} 2.1$ - $\mathrm{TOPO}^{\mathbb{R}}$ vector to form plasmid HlyBD/TOPO. This plasmid was digested with $S a c \mathrm{I}$ and $\mathrm{BamHI}$ and ligated into the similarly-restricted expression vector pSTV28, resulting in HlyBD/pSTV28.

The sequences of all of the genes amplified by PCR were confirmed by DNA sequencing.

\section{Extracellular Expression of $T$. fusca cutinase}

E. coli BL21(DE3) cells were transformed with cutinaseHlyAs/pET-20b(+) complex with HlyBD/pSTV28. The engineered strains were grown in TB medium, containing $100 \mu \mathrm{g} / \mathrm{ml}$ of ampicillin and $30 \mu \mathrm{g} / \mathrm{ml}$ of

Table 2 Monomeric products released from cutin hydrolysis by cutinase and cutinase-HlyAs, respectively

\begin{tabular}{ccc}
\hline Cutin hydrolysis products & $\begin{array}{c}\text { Cutinase Hydrolysis } \\
\text { Area (\%) }\end{array}$ & Cutinase-HlyAs Hydrolysis Area (\%) \\
\hline Hexadecanoic acid & 34.17 & 31.78 \\
Octadecanoic acid & 33.63 & 35.57 \\
9-Octadecenoic acid & 1.16 & 1.18 \\
9,12-Octadecadienoic acid & 1.08 & 1.65 \\
16-Hydroxy hexadecanoic acid & 0.34 & 0.40 \\
18-Hydroxyoctadeca-9,12-dienoic acid & 1.46 & 1.55 \\
\hline
\end{tabular}

Cutin hydrolysis by cutinase-HlyAs and cutinase were incubated in $25 \mathrm{mM}$ potassium phosphate buffer $(\mathrm{pH} 8.0)$ at temperature $50^{\circ} \mathrm{C}$ for $18 \mathrm{~h}$. The results are the averages of triplicate assays. 
Table 3 Oligonucleotide primers for the construction process

\begin{tabular}{cc}
\hline Name & Primers $\mathbf{5}^{\prime} \rightarrow \mathbf{3}^{\prime}$ \\
\hline cutinase-F & GTAATCCATATGGCCAACCCCTACGAGCGC \\
cutinase-HlyAs-F & CTCCACCTGCCCGTTCTAGCCTATGGAAGTC \\
cutinase-HlyAs-R & GACTTCCATAGGCTAAGAACGGGCAGGTGGAG \\
HlyAs-R & CCGCTCGAGTATGCTGATGCTGTCAAAG \\
HlyAs-MF & GCCAGTGATTITCgTATGGACGGAACTC \\
HlyAs-MR & GAGTTCCGTCGATACGAAAAATCACTGGC \\
HlyBD-F & CGGCGAGCTCGGATCTTGTCATAAATTG \\
HlyBD-R & CCACGGATCCTAACGCTCATGTAAAC \\
\hline
\end{tabular}

chloramphenicol, on a rotary shaker at $37^{\circ} \mathrm{C}$ until an optical density of 1.5 at $600 \mathrm{~nm}$ was reached. Isopropyl1 -thio- $\beta$-D-galactopyranoside (IPTG) was added at that point, to a final concentration of $0.4 \mathrm{mM}$ to induce expression. After induction, the culture was grown at $25^{\circ} \mathrm{C}$. Cell growth $\left(\mathrm{OD}_{600}\right)$ and enzyme activity were measured at regular intervals.

\section{Purification of Recombinant Cutinase}

The recombinant cutinase-HlyAs was purified as following. The culture medium of the engineering $E$. coli BL21(DE3) was centrifuged at $10,000 \times g$ for $20 \mathrm{~min}$ at $4^{\circ} \mathrm{C}$, and then $\left(\mathrm{NH}_{4}\right)_{2} \mathrm{SO}_{4}$ was slowly added to the culture supernatant, with stirring, to a final concentration of $70 \%(\mathrm{w} / \mathrm{v})$. The precipitated protein was collected and dissolved in buffer $\mathrm{A}$ (20 mM Tris- $\mathrm{HCl}, \mathrm{pH}$ 8.0), and then dialyzed against 2 liters of buffer A overnight. The sample was filtered (0.22 $\mu \mathrm{m})$ and loaded onto a DEAE-Sepharose FF column preequilibrated with buffer A. The column was eluted at a flow rate of $1 \mathrm{ml} / \mathrm{min}$ with a five-column-volume linear gradient of 0 to $1 \mathrm{M} \mathrm{NaCl}$ in buffer $\mathrm{A}$. The fractions containing PNPB hydrolase activity were pooled, and then dialyzed against 1 liter of buffer $\mathrm{A}$ at $4{ }^{\circ} \mathrm{C}$ overnight. The dialyzed sample was subjected to monoQ chromatography using a procedure similar to the one described above. The purified enzyme was concentrated by ultrafiltration (30 $\mathrm{kDa}$ cut-off membrane, Amicon) and stored at $-20^{\circ} \mathrm{C}$.

The recombinant cutinase, which was expressed by SecB-dependent type II pathway in E. coli BL21(DE3), was purified according to the previous report [30].

\section{Enzyme Characterization of Cutinase-HlyAs}

Esterase activity, cutinase activity, the optimal temperature/pH, the thermostability and $\mathrm{pH}$ stability of cutinase and cutinase-HlyAs were performed as previously described [30,35].

\section{Catalytic Activity of Cutinase-HlyAs toward Totton fiber/ Wettability of Cotton Fabric}

For a typical wettability assay, 300 units of enzyme and 0.1 $\mathrm{g}$ of cotton fabric were added to $25 \mathrm{mM}$ Tris- $\mathrm{HCl}, \mathrm{pH} 8.0$, in a final volume of $40 \mathrm{ml}$. The mixture was shaken at 200 $\mathrm{rpm}$ for $3 \mathrm{~h}$ in a water bath pre-equilibrated to the desired temperature. The treated swatches were tested for wettability according to Degani et al [29].

\section{Acknowledgements}

This work was supported financially by the National High-tech Research and Development Program of China (2009AA02Z204), the National Natural Science Foundation of China (30970057 and 31100048), the Key Program of National Natural Science Foundation of China (20836003), and the 111 Project (No. 111-2-06)

\section{Author details}

${ }^{1}$ State Key Laboratory of Food Science and Technology, Jiangnan University, 1800 Lihu Ave, Wuxi, Jiangsu 214122, China. ${ }^{2}$ School of Biotechnology and Key Laboratory of Industrial Biotechnology, Ministry of Education, Jiangnan University, 1800 Lihu Ave, Wuxi, Jiangsu 214122, China. ${ }^{3}$ Department of Medicinal Chemistry, University of Michigan, Ann Arbor, Michigan 48109, USA.

\section{Authors' contributions}

JW supervised the project, SC designed the study, LQS carried out the experiments and drafted the manuscript, LY and RWW participated in the construction of the plasmids, critically revised and corrected the manuscript, JW and JC provided critical discussion. All authors read and approved the final manuscript.

\section{Competing interests}

The authors declare that they have no competing interests.

Received: 23 November 2011 Accepted: 12 January 2012 Published: 12 January 2012

\section{References}

1. Mergulhao FJM, Summers DK, Monteiro GA: Recombinant protein secretion in Escherichia coli. Biotechnol Adv 2005, 23:177-202.

2. Chen S, Liu Z, Chen J, Wu J: Study on improvement of extracellular production of recombinant Thermobifida fusca cutinase by Escherichia coli. Appl Biochem Biotechnol 2011, 165:666-675.

3. Yamabhai M, Emrat S, Sukasem S, Pesatcha P, Jaruseranee $N$, Buranabanyat B: Secretion of recombinant Bacillus hydrolytic enzymes using Escherichia coli expression systems. J Biotechnol 2008, 133:50-57.

4. Binet $R$, Letoffe $S$, Ghigo JM, Delepelaire P, Wandersman C: Protein secretion by Gram-negative bacterial ABC exporters-a review. Gene 1997, 192:7-11.

5. Omori K, Idei A: Gram-negative bacterial ATP-binding cassette protein exporter family and diverse secretory proteins. J Biosci Bioeng 2003, 95:1-12.

6. Chung CW, You J, Kim K, Moon Y, Kim H, Ahn JH: Export of recombinant proteins in Escherichia coli using $A B C$ transporter with an attached lipase $A B C$ transporter recognition domain (LARD). Microb Cell Fact 2009, 8.

7. Song JK, Oh JY, Eom GT, Song BK: High-level secretion of Pseudomonas fluorescens type I secretion system-dependent lipase in Serratia marcescens. J Biotechnol 2007, 130:311-315.

8. Angkawidjaja C, Kuwahara K, Omori K, Koga Y, Takano K, Kanaya S: Extracellular secretion of Escherichia coli alkaline phosphatase with a Cterminal tag by type I secretion system: purification and biochemical characterization. Protein Eng Des Sel 2006, 19:337-343.

9. Akatsuka H, Binet R, Kawai E, Wandersman C, Omori K: Lipase secretion by bacterial hybrid ATP-binding cassette exporters: molecular recognition of the LipBCD, PrtDEF, and HasDEF exporters. J Bacteriol 1997, 179:4754-4760.

10. Welch RA, Dellinger EP, Minshew B, Falkow S: Haemolysin contributes to virulence of extra-intestinal E. coli infections. Nature 1981, 294:665-667.

11. Gentschev I, Dietrich G, Goebel W: The E-coli alpha-hemolysin secretion system and its use in vaccine development. Trends Microbiol 2002, 10:39-45. 
12. Blight MA, Holland IB: Heterologous protein secretion and the versatile Escherichia coli haemolysin translocator. Trends Biotechnol 1994, 12:450-455.

13. Gentschev I, Fensterle J, Schmidt A, Potapenko T, Troppmair J, Goebel W, Rapp UR: Use of a recombinant Salmonella enterica serovar Typhimurium strain expressing C-Raf for protection against C-Raf induced lung adenoma in mice. Bmc Cancer 2005, 5.

14. Zhu CR, Ruiz-Perez F, Yang ZL, Mao Y, Hackethal VL, Greco KM, Choy W, Davis K, Butterton JR, Boedeker EC: Delivery of heterologous protein antigens via hemolysin or autotransporter systems by an attenuated ler mutant of rabbit enteropathogenic Escherichia coli. Vaccine 2006, 24:3821-3831

15. Sugamata $Y$, Shiba T: Improved secretory production of recombinant proteins by random mutagenesis of hlyB, an alpha-hemolysin transporter from Escherichia coli. Appl Environ Microbiol 2005, 71:656-662.

16. Narayanan N, Khan M, Chou CP: Enhancing functional expression of heterologous lipase B in Escherichia coli by extracellular secretion. J Ind Microbiol Biotechnol 2010, 37:349-361.

17. Low KO, Mahadi NM, Abdul Rahim R, Rabu A, Abu Bakar FD, Abdul Murad AM, Illias RM: Enhanced secretory production of hemolysinmediated cyclodextrin glucanotransferase in Escherichia coli by random mutagenesis of the $A B C$ transporter system. J Biotechnol 2010, 150:453-459.

18. Gentschev I, Hess J, Goebel W: Change in the cellular localization of alkaline phosphatase by alteration of its carboxy-terminal sequence. $\mathrm{Mol}$ Gen Genet 1990, 222:211-216.

19. Bakkes PJ, Jenewein S, Smits SHJ, Holland IB, Schmitt L: The Rate of Folding Dictates Substrate Secretion by the Escherichia coli Hemolysin Type 1 Secretion System. J Biol Chem 2010, 285.

20. Dutta K, Sen S, Veeranki VD: Production, characterization and applications of microbial cutinases. Process Biochem 2009, 44:127-134.

21. Acero EH, Ribitsch D, Steinkellner G, Gruber K, Greimel K, Eiteljoerg I, Trotscha E, Wei R, Zimmermann W, Zinn M, et al: Enzymatic Surface Hydrolysis of PET: Effect of Structural Diversity on Kinetic Properties of Cutinases from Thermobifida. Macromolecules 2011, 44:4632-4640.

22. Silva C, Da S, Silva N, Matama T, Araujo R, Martins M, Chen S, Chen J, Wu J, Casal $M$, et al: Engineered Thermobifida fusca cutinase with increased activity on polyester substrates. Biotechnol J 2011, 6:1230-1239.

23. Chen S, Su LQ, Billig S, Zimmermann W, Chen J, Wu J: Biochemical characterization of the cutinases from Thermobifida fusca. J Mol Catal BEnzym 2010, 63:121-127.

24. Maeda H, Yamagata Y, Abe K, Hasegawa F, Machida M, Ishioka R, Gomi K, Nakajima T: Purification and characterization of a biodegradable plasticdegrading enzyme from Aspergillus oryzae. Appl Microbiol Biotechnol 2005, 67:778-788.

25. Vertommen MA, Nierstrasz VA, Veer M, Warmoeskerken MM: Enzymatic surface modification of poly(ethylene terephthalate). J Biotechnol 2005, 120:376-386

26. Alisch-Mark M, Herrmann A, Zimmermann W: Increase of the hydrophilicity of polyethylene terephthalate fibres by hydrolases from Thermomonospora fusca and Fusarium solani f. sp. pisi. Biotechnol Lett 2006, 28:681-685.

27. de Barros DP, Fonseca LP, Cabral JM, Weiss CK, Landfester K: Synthesis of alkyl esters by cutinase in miniemulsion and organic solvent media. Biotechnol J 2009, 4:674-683.

28. Borreguero I, Carvalho CML, Cabral JMS, Sinisterra JV, Alcantara AR: Enantioselective properties of Fusarium solani pisi cutinase on transesterification of acyclic diols: activity and stability evaluation. $J \mathrm{Mo}$ Catal B-Enzym 2001, 11:613-622.

29. Degani O, Gepstein S, Dosoretz CG: Potential use of cutinase in enzymatic scouring of cotton fiber cuticle. Appl Biochem Biotech 2002, 102:277-289.

30. Chen S, Tong X, Woodard RW, Du G, Wu J, Chen J: Identification and characterization of bacterial cutinase. J Biol Chem 2008, 283:25854-25862

31. Kwon MA, Kim HS, Yang TH, Song BK, Song JK: High-level expression and characterization of Fusarium solani cutinase in Pichia pastoris. Protein Expres Purif 2009, 68:104-109.

32. Ferreira BS, Calado CRC, van Keulen F, Fonseca LP, Cabral JMS, da Fonseca MMR: Towards a cost effective strategy for cutinase production by a recombinant Saccharomyces cerevisiae: strain physiological aspects. Appl Microbiol Biot 2003, 61:69-76.
33. Jun $H$, Bing Y, Keying Z, Xuemei D, Daiwen C: Thermostable carbohydrate binding module increases the thermostability and substrate-binding capacity of Trichoderma reesei xylanase 2. N Biotechnol 2009, 26:53-59.

34. Sun J, Wang H, Lv W, Ma C, Lou Z, Dai Y: Construction and characterization of a fusion beta-1,3-1,4-glucanase to improve hydrolytic activity and thermostability. Biotechnol Lett 2011, 33:2193-2199.

35. Zhang Y, Chen S, Xu M, Cavoco-Paulo A, Wu J, Chen J: Characterization of Thermobifida fusca cutinase-carbohydrate-binding module fusion proteins and their potential application in bioscouring. Appl Environ Microbiol 2010, 76:6870-6876.

doi:10.1186/1475-2859-11-8

Cite this article as: Su et al: Extracellular overexpression of recombinant Thermobifida fusca cutinase by alpha-hemolysin secretion system in $E$. coli BL21(DE3). Microbial Cell Factories 2012 11:8.

\section{Submit your next manuscript to BioMed Central and take full advantage of:}

- Convenient online submission

- Thorough peer review

- No space constraints or color figure charges

- Immediate publication on acceptance

- Inclusion in PubMed, CAS, Scopus and Google Scholar

- Research which is freely available for redistribution

Submit your manuscript at www.biomedcentral.com/submit
C Biomed Central 